\title{
AlEXANDER RENKL
}

Learning for Later Teaching: an Exploration of Mediational Links Between Teaching Expectancy and Learning Results 
teaching as a central component, for example, the jigsaw method (Aronson, 1984; Aronson, Blaney, Stephan, Sikes, \& Snapp, 1978), the reciprocal teaching approach (Brown \& Campione, 1990; Palincsar \& Brown, 1984), the reciprocal tutoring method (Fantuzzo, King, \& Heller, 1992; Fantuzzo, Riggio, Connelly, \& Dimeff, 1989), and the scripted cooperation and cooperative teaching script procedures (Lambiotte et al., 1987; O’Donnell \& Dansereau, 1992).

The effects of learning by teaching are often not only attributed to the teaching activity itself, but also to the pure expectation of a later teaching demand. The probably most cited study that investigated the effects of a teaching expectancy was conducted by Bargh and Schul (1980). They compared an experimental group which expected to teach the content of a text passage to another person with a control group which expected only to answer some questions. The available time to study the text was kept constant for both groups. The learners with teaching expectancy outperformed the control group in a final test. A positive effect of a teaching expectancy was also found by Benware and Deci (1984), although only with respect to high-level post-test items, not with regard to rote questions. Furthermore, the subjects with teaching expectancy were more intrinsically motivated. Ross and DiVesta (1976) also concluded that the teaching expectancy they induced fostered learning. However, their data showed no clear evidence for that judgement. Nevertheless their study is of interest, because it shows that a teaching expectancy can elicit anxiety and, therefore, have detrimental effects. Schommer, Crouse, and Rhodes (1992), too, did not find any significant effect of a teaching expectancy. However, as this study had another main focus, no detailed information was provided. Negative effects were reported by Ehly, Keith, and Bratton (1987). When learning time was kept constant, subjects with teaching expectancy learned less than persons preparing for a test. Unfortunately, no process data were available to explain this negative expectancy effect.

As the discussion of the studies on the effects of a teaching expectancy has shown, the state of affairs is quite unclear. A major disadvantage of the cited studies is that the mediational links between the teaching expectancy and the learning results were not investigated, or investigated only by including one mediator variable as in the cases of Ross and DiVesta (1976; anxiety) and Benware and Deci (1984; intrinsic motivation; however, the relation between intrinsic motivation and learning was not reported). Thus, in the case of the absence of positive effects, it remains open whether the supposed mediational variables (e.g., more in-depth processing of text information) were not affected by the teaching expectancy or whether they were affected, but did not influence the learning results. Another reason for insignificant teaching expectancy effects might be that there are simultaneously positive and negative mediational links. For example, a teaching expectancy may result in less superficial processing of learning materials and, at the same time, elicit high anxiety which results in an overall effect of zero.

An additional restriction of the studies cited above is that until now only text learning has been investigated. It may be that in learning from texts, the intention to learn more intensively and more strategically does not result in better learning results. For example, a study by Gräsel (1990) showed that university students who described themselves in a questionnaire as strategic readers (trait) actually elaborated more on a text, indicated by the fact that in a subsequent test phase they produced more inferences. However, in summarizing the text, the more strategic students produced even fewer important 
propositions and made more errors on comprehension questions. Mandl and Ballstaedt (1982) also found that a high level of elaboration impaired learning. It may be that an active and strategic approach to learning, as it is supposed to be induced by a teaching expectancy, is more effective with other forms of learning, for example, learning by doing or learning from worked-out examples (Zhu \& Simon, 1987). In the present study, students had to learn from worked-out examples. It has been shown that an active processing of such learning materials leads to better learning results (Chi, Bassok, Lewis, Reimann, \& Glaser, 1989; Reimann \& Schult, 1991).

\section{Research Questions}

In the present investigation, university students of education had to learn from worked-out probability calculus problems that required active self-explanations in order to gain a sufficient understanding of the solutions (cf. Chi et al., 1989). This is not only typical of psychological experiments on learning through worked-out examples, but also of common textbook examples (see Figure 1a and b). One half of the subjects expected that they would be required to explain similar worked-out problems to a third person. The other half expected only to be tested on similar problems. The significance of several mediational links between the teaching expectancy and the learning results was explored.

With respect to the processing of the worked-out examples, a teaching expectancy is supposed to result in a less -superficial processing. If somebody expects that $\mathrm{s} / \mathrm{he}$ will have to explain similar problems later on, s/he is probably less likely to skip impasses in understanding, and s/he needs more time to really figure out the rationale underlying the solution steps. Therefore, persons who expect to teach presumably assign more time to each worked-out example they study. In addition, it is hypothesized that the less superficial the processing the greater is the learning effect. Of course, it is also assumed that learners with more prior knowledge in mathematics can process the examples more quickly and, nevertheless, learn effectively. Thus, when testing whether superficiality of processing is a mediating link between teaching expectancy and learning results, it is planned to control for the level of prior knowledge.

Research has shown that experts, compared to novices, spend more time for proper encoding and elaboration of the initial givens of a problem (Bédard \& Chi, 1992). A sound problem representation is, in turn, a prerequisite for effective problem solving. Thus, assigning relatively much time to the encoding of a problem is assumed to lead to more high-quality self-explanations of the worked-out examples and, consequently, to better learning results. As in the case of superficiality, the learners with teaching expectancy are expected to be more motivated to gain a sound understanding of the posed problem and, therefore, to allocate more time for initial problem elaborations. Prior knowledge will be controlled when testing the association between initial problem elaboration and teaching expectancy as well as learning results.

With regard to motivational-affective effects, the study by Ross and DiVesta (1976) suggests that the teaching expectancy can elicit anxiety. From a theoretical point of view, anxiety during learning is evoked by a demand with which a person cannot easily cope and by a possible failure leading to certain consequences that are negatively evaluated by 
In an aptitude test for aircraft pilots, $40 \%$ of the applicants do not pass the physical examination and $60 \%$ do not pass the psychological tests. $20 \%$ of the applicants fail because of the physical and the psychological examination. What is the probability that two randomly selected applicants fit the job?

In an aptitude test for aircraft pilots, $40 \%$ of the applicants do not pass the physical examination and $60 \%$ do not pass the psychological tests. $20 \%$ of the applicants fail because of the physical and the psychological examination. What is the probability that two randomly selected applicants fit the job?

Probability of physical deficits:

$40 / 100=2 / 5$

Probability of psychological deficits:

$60 / 100=3 / 5$

Probability of physical and psychological deficits

$20 / 100=1 / 5$. 
In an aptitude test for aircraft pilots, $40 \%$ of the applicants do not pass the physical examination and $60 \%$ do not pass the psychological tests. $20 \%$ of the applicants fail because of the physical and the psychological examination. What is the probability that two randomly selected applicants fit the job?

Probability of physical deficits:

$40 / 100=2 / 5$

$\begin{array}{ll}\text { Probability of psychological deficits: } & 60 / 100=3 / 5 ;\end{array}$

$\begin{array}{ll}\text { Probability of physical and psychological deficits: } & 20 / 100=1 / 5\end{array}$

\begin{tabular}{lr}
\hline Probability of non-fit: & $2 / 5+3 / 5-1 / 5=4 / 5$ \\
Probability of fit: & $1-4 / 5=1 / 5$.
\end{tabular}

In an aptitude test for aircraft pilots, $\mathbf{4 0 \%}$ of the applicants do not pass the physical examination and $60 \%$ do not pass the psychological tests. $20 \%$ of the applicants fail because of the physical and the psychological examination. What is the probability that two randomly selected applicants fit the job?

Probability of physical deficits: $40 / 100=2 / 5$;

Probability of psychological deficits: $\quad 60 / 100=3 / 5$

Probability of physical ans psychological deficits: $20 / 100=1 / 5$.

Probability of non-fit: $2 / 5+3 / 5-1 / 5=4 / 5 ;$

Probability of fit: $\quad 1-4 / 5=1 / 5$.

Probability of two persons that fit:

$1 / 5 \cdot 1 / 5=1 / 25$

Answer:

The probability that two randomly selected persons fit for the job is $1 / 25$.

Figure 1a and $b$. Screens of one worked-out example. 
a person. Anxiety can be elicited under both experimental conditions, especially because the content domain is mathematics. It has repeatedly been shown that demands in this domain elicit tremendous achievement anxiety in a substantial proportion of students of education (Gruber, 1994; Renkl, 1994; Zeidner, 1991). In addition, the expectation to teach can increase the pressure to learn successfully and, consequently, elevate anxiety at least by two factors. First, a person may conceive that a deeper level of understanding is necessary when the learning contents should be taught later on, in comparison to a test demand. Second, whereas working on a test is a relatively "private" situation with no other person directly observing the performance, teaching is public and negative evaluations of others may be directly perceived during this activity.

With respect to intrinsic motivation, no clear expectancy can be formulated. On the one hand, learning under the perspective of applying the acquired knowledge (in this case: instructing others) should foster intrinsic orientation. Benware and Deci (1984), who found higher intrinsic motivation under a teaching expectancy, could confirm this hypothesis in their study. On the other hand, the teaching expectancy possibly heightens anxiety which presumably is negatively associated with intrinsic motivation. An elevated anxiety level is supposed to interfere with an intrinsic orientation. Thus, intrinsic motivation can be both negatively and positively affected by a teaching demand.

However, not only anxiety and intrinsic motivation are supposed to be interrelated, but also relations between the other supposed mediators seem to be possible. Therefore, their interrelations will be explored.

In sum, the following research questions are addressed:

(1) Does a teaching expectancy influence learning processes in cognitive and motivational-affective respects? More specifically, it is explored to what extent the following variables are influenced: anxiety (affective state anxiety and worry), intrinsic motivation, superficiality of processing, and initial problem elaboration.

(2) What are the interrelations between the potential mediator variables and how are they related to prior knowledge?

(3) Do the potential mediator variables influence learning results?

(4) What variables can actually be regarded as mediators?

(5) Does a teaching expectancy affect learning results?

The teaching expectancy is the independent variable, anxiety (affective state anxiety and worry), intrinsic motivation, superficiality of processing, and initial problem elaboration are mediators, and the learning results are the dependent variable.

\section{Method}

\section{Sample and Design}

Thirty-six beginning students of education from the University of Munich participated in the present experimental study. They volunteered to take part in this investigation without any credit. The only external incentive was that they had been told that the topic of probability calculus was part of a later compulsory statistics course. Eighteen subjects were randomly assigned to the experimental group (with teaching expectancy) and to 
the control group respectively. The experimental group learned by studying worked-out examples with the expectation that they would have to explain similar problems to a third person who was a novice in probability calculus. However, the teaching phase was not realized. The control group merely expected to solve similar problems later on.

\section{Worked-out Examples}

The worked-out examples were presented on a computer monitor. The solution to each problem was demonstrated on four screen pages. Figure 1a and b shows the four pages of one such worked-out example. On the first page, the problem was presented (see the upper part of Figure 1a). After encoding it, the subjects could go to the next page where the first solution step was given in addition to the problem formulation (see the lower part of Figure 1a). After explaining this solution step to themselves, the subjects proceeded to the following page with the next solution step (see the upper part of Figure 1b). The amount of time spent on each screen was automatically recorded. The complete solution of each problem was presented on the fourth page (see the lower part of Figure 1b). On the next page, a new problem was presented. The subjects were free to determine the speed of processing of the worked-out examples. An external pacing, for example, by fixed presentation time spans for the pages, would have interfered with the learners' strategies and would have diminished ecological validity. In addition, this would lead to an interference with the experimental variation. Nonetheless, in order to keep constant the time-on-task for each person and, thereby for both groups, each person had 25 min to study the worked-out examples. Differences in speed or superficiality of processing caused the number of examples inspected by different persons to vary. In order to prevent the faster subjects from having the opportunity to learn through inspection of further examples with different deep structures and, consequently, acquiring a broader knowledge base, merely four types of deep structure were used. Within the available time, which was determined according to the results of pilot studies, every subject could process the first four problems encountered and, hence, each type of deep structure. Faster persons were confronted with problems with new surface features (i.e., new numbers, new objects), but not new deep structures.

\section{Instruments and Measures}

\section{Mathematical pretests}

Computational and algebraic preknowledge was assessed by a subsample of items used in the algebra test of Lienert and Hofer (1977) called Mathematiktest für Abiturienten und Studienanfänger (Mathematics test for 13th graders and university freshmen). For this 10 -item scale, a reliability of 0.76 (Cronbach's $\alpha$ ) was determined. In addition, six relatively simple probability calculus items were employed as pretest (e.g., "If you play the dice twice, what is the probability of two 6s?"). A Cronbach's $\alpha$ of 0.69 was calculated. 


\section{On-line data}

The time span that the subjects allocated to each page was automatically recorded. The percentage of time assigned by the subjects to the initial problem formulation pages was used as indicator of the effort to gain a sound problem representation. In the following, this variable is called initial problem elaboration. The number of screens that were inspected by an individual subject was, under control for prior knowledge, an indicator of the superficiality of studying.

\section{Anxiety and intrinsic motivation questionnaires}

In order to measure the amount of anxious tension during the study of the workedout examples, the same inventory as in the study of Ross and DiVesta (1976) was employed, that is, the state scale of the STAI (in the present case: German version by Laux, Glanzmann, Schaffner, \& Spielberger, 1981; Cronbach's $\alpha$ : 0.93). This measure addresses, however, primarily the affective component of achievement anxicty. For this reason, the extent to which anxious task-irrelevant cognitions were elicited in the learning phase was additionally assessed by seven worry items (e.g. "I worried whether I could understand the examples"; Cronbach"s $\alpha: 0.7(0)$. Intrinsic motivation was measured by a scale developed by Prenzel, Eitel, Holzbach, Schoenheinz, and Schweiberer (1993), based on the theory of Deci, Ryan and co-workers (Deci, Vallerand, Pelletier, \& Ryan, 1991; Ryan, Connell, \& Deci, 1985) (e.g.. "Studying the examples was fun"; 5 Items; Cronbach's $\alpha$ : 0.85).

\section{Post-test}

The post-test that measured the learning results included 15 items. Three items were relatively simple problems similar to those in the pretest. The remaining 12 items, which addressed deep understanding, were constructed according to the following categories (see Figure 2): four items were identical to the problems that were presented as the first four worked-out examples, except for some irrelevant information embedded in them (i.e., same deep structure, similar surface structure, irrelevant information); four items had the same deep structure, but a different surface structure; four items had a similar surface structure, but the deep structure was changed. A Cronbach's $\alpha$ of 0.84 was calculated for the post-test.

\section{Procedure}

The subjects worked in individual sessions of about two hours. In the beginning, the subjects were told that they were participating in a study on learning probability calculus by studying texts and worked-out examples. Then the mathematical pretests were presented. In order to provide or re-activate basic knowledge that allows for understanding the worked-out examples to be studied later on, a short instructional text on basic principles of probability calculus (e.g., definition of probability, multiplication principle for independent events) was given to the subjects. The comprehension of the 
Same deep structure - similar surface structure - irrelevant information

In an aptitude test for aircraft pilots, $40 \%$ of the applicants do not pass the physical examination and $60 \%$ do not pass the psychological tests. $20 \%$ of the applicants fail because of the physical and the psychological examination. $40 \%$ merely failed to pass the psychological tests. What is the probability that two randomly selected applicants fit the job?

Same deep structure - different surface structure

Production errors cause $15 \%$ of pencils to have the wrong length and $10 \%$ the wrong thickness. In $5 \%$ of the cases both faults are present. If two pencils are randomly selected, what is the probability that both are perfect ones?

Different deep structure - similar surface structure

In an aptitude test for aircraft pilots, $40 \%$ of the applicants do not pass the physical examination and $60 \%$ do not pass the psychological tests. $20 \%$ of the applicants fail because of the physical and the psychological examination. What is the probability that at least one out of two randomly selected applicants fits the job?

Figure 2. Types of post-test items and corresponding examples.

basic concepts was tested by a criterion-referenced test which was evaluated immediately. If an item was not correctly answered, the experimenter gave a semi-standardized explanation and had the subject re-read the corresponding text passage.

After this procedure, the subjects were informed that they had to study worked-out examples for $25 \mathrm{~min}$. At this point the experimental variation was set: The experimenter told the experimental group that, later on, they would have to explain to a third person problems similar to the following ones. It was specified that this third person was a novice in probability calculus, but that $\mathrm{s} / \mathrm{he}$ also had read the instructional text on basic principles of probability calculus. The control group was told that they would have to work on similar problems later on. The worked-out examples were presented in the way described above. During the study of the examples, the subjects had the instructional text on the relevant basic principles of probability calculus at hand. 
After studying the worked-out examples, the subjects filled in the questionnaires on anxiety and intrinsic motivation. Finally, the post-test was presented. For the control group, this was an expected event. The experimental group was told that we wanted to study how their later explanations depend on their knowledge level and the test was, thus, necessary. Before the subjects left, they were debriefed.

\section{Results}

In the following data presentation, the bivariate relations (t-tests, zero-order correlations) are first reported. If the pretest scores (prior knowledge) were significantly related to the respective variables, partial correlations or analyses of covariance controlling for prior knowledge were computed.

First of all, it was checked whether both groups had similar prior mathematical knowledge. With respect to both pretests (algebra and probability calculus), very small and thus insignificant differences were obtained (see Table 1). Hence, the experimental and the control group were comparable with respect to the indicators of cognitive prerequisites assessed in this study.

Table 1

Group Differences: Means (Standard Deviations), T-tests and Effect Sizes

\begin{tabular}{|c|c|c|c|c|c|}
\hline & $\begin{array}{l}\text { Control } \\
\text { group }\end{array}$ & $\begin{array}{l}\text { Experimental } \\
\text { group }\end{array}$ & $t$-value ${ }^{*}$ & $p$-value & effect size \\
\hline Pretest - algebra & $0.50 \quad(0.25)$ & $0.51 \quad(0.26)$ & 0.07 & .948 & .04 \\
\hline Pretest - probability & $1.06(1.39)$ & $1.11 \quad(1.37)$ & 0.12 & .905 & .04 \\
\hline Intrinsic motivation & $3.27(1.01)$ & $2.60(0.88)$ & -2.11 & .042 & -.69 \\
\hline State anxiety & $2.34(0.82)$ & $2.72(0.72)$ & 1.46 & $.076 \div$ & .48 \\
\hline Worry & $2.51 \quad(0.92)$ & $2.33(0.66)$ & -0.65 & 一 & -.22 \\
\hline Superficiality of studying & $42.89(15.95)$ & $33.06(10.01)$ & -2.22 & $.017^{\dagger}$ & -.72 \\
\hline Problem elaboration & $31.45(10.90)$ & $28.25(10.91)$ & -.88 & 一 & -.29 \\
\hline Post-test & $11.22(6.59)$ & $11.28(7.27)$ & 0.02 & .981 & .01 \\
\hline
\end{tabular}

Note: ${ }^{*} \mathrm{df}=34$; tone-tailed test of significance; fin accord with the hypotheses, a one-tailed test of significance was planned, however, the difference between groups contradicts the expectations, thus, no test of significance is necessary.

\section{Effects of Teaching Expectancy on Potential Mediators}

As Table 1 shows, the teaching expectancy had a statistically and practically significant negative effect on intrinsic motivation $(d=-.69)$. For state anxiety which was heightened by the teaching expectancy, a medium effect size of $d=.48$ emerged. However, due to the present sample size, this group difference would only reach the level of significance if the alpha error-level was set to $10 \%$. Worry was not significantly affected by the experimental variation (see Table 1).

The superficiality of processing was substantially reduced by the teaching expectancy $(d=-.72)$. Whereas the subjects of the control group on average inspected 42.89 pages 
(i.e., 10-11 worked-out examples), the corresponding mean of the subjects with teaching expectancy was only 33.06 (i.e., 8-9 worked-out examples). Based on the computed learning time per worked-out example, this result demonstrated that the subjects with teaching expectancy on average assigned about $40 \mathrm{sec}$ more to each problem than the control group (181 sec vs $140 \mathrm{sec}$ ).

Problem elaboration was not significantly affected by the experimental variation. The subjects in both groups allocated about $30 \%$ of the learning time for building an initial problem elaboration. Given that each worked-out example was presented on four pages, this result indicated that the first page on average was inspected for a relatively longer period of time than the other pages (the expected value for each page under a null hypothesis: $25 \%$ of the learning time).

\section{Interrelations Between Potential Mediators and Between Mediators and Prior Knowledge}

The interrelations between the potential mediator variables are shown in Table 2 . As expected, the anxiety scores correlated substantially with each other $(r=.55)$ and negatively with intrinsic motivation (worry: $r=-.34$; state anxiety: $r=-.36$; see Table 2). The cognitive variables superficiality of processing and problem elaboration were neither significantly correlated with each other nor with the motivational-affective variables, except for the negative association between superficiality of processing and state anxiety $(r=-.32)$. The latter finding indicates that persons experiencing high state anxiety tend to assign much learning time to single worked-out examples.

Table 2

Intercorrelation of Variables

\begin{tabular}{|c|c|c|c|c|c|c|c|c|}
\hline & & (2) & (3) & (4) & $(5)$ & (6) & (7) & (8) \\
\hline $\begin{array}{l}(1) \\
(2) \\
(3) \\
(4) \\
(5) \\
(6) \\
(7) \\
(8)\end{array}$ & $\begin{array}{l}\text { pretest - algebra } \\
\text { pretest - probability } \\
\text { post-test } \\
\text { problem elaboration } \\
\text { superficiality of studying } \\
\text { state anxiety } \\
\text { worry } \\
\text { intrinsic motivation }\end{array}$ & -.06 & $\begin{array}{c}.03 \\
-.53 \dagger\end{array}$ & $\begin{array}{r}-.32 \dagger \\
.44 \dagger \\
.37 \dagger\end{array}$ & $\begin{array}{l}.03 \\
.21 \\
.23 \\
.07\end{array}$ & $\begin{array}{l}.00 \\
-.23 \\
-.25^{*} \\
-.10 \\
-.32 \dagger\end{array}$ & $\begin{array}{l}-.23 \\
-.28 \dagger \\
-.40 \dagger \\
-.04 \\
-.19 \\
.55 \dagger\end{array}$ & $\begin{array}{c}-.10 \\
-.08 \\
.05 \\
.24 \\
.17 \\
-.36 \dagger \\
-.34 \dagger\end{array}$ \\
\hline
\end{tabular}

Note: ${ }^{*} p<.10 ; \dagger p<.05$.

With respect to the association between prior knowledge and the potential mediator variables mainly insignificant correlations were obtained. Prior knowledge in probability calculus was just significantly associated with worry $(r=-.28)$ and problem elaboration $(r=.44$; see Table 2$)$. This means that subjects with high prior knowledge in probability calculus tend to worry less and devote more learning time to construct a proper initial problem elaboration. Algebraic preknowledge was merely associated with problem elaboration $(r=-.32, p<.05)$. Persons with high prior algebraic knowledge tend to assign less time to initial problem elaboration. 


\section{Relations Between Potential Mediators and Learning Results}

The learning results were significantly correlated with worry $(r=-.40, p<.25)$, problem elaboration $(r=.37, p<.05)$, and, at the $10 \%$ level, with state anxiety $(r=-.25)$. Accordingly, the subjects who showed low anxiety and assigned much time to the initial problem elaboration tended to be successful in working on the post-test. When controlling for both pretests, worry was still significantly related to the learning results (partial correlation: $-.30 ; p<.05$ ) which indicates that worry actually impeded learning. For initial problem elaboration, which correlated positively with the probability pretest $(r=.44)$ and negatively $(r=-.32)$ with the algebra pretest (see Table 2$)$, the respective partial correlation (controlling for both pretests) failed to reach the level of significance $(.22$, n.s.).

\section{Mediator and Experimental Effects}

With regard to the learning results (post-test), the experimental group did not differ from the control group (see Table 1). As Table 2 shows, the probability calculus pretest was, in contrast to the algebra pretest, substantially associated with the learning results. However, even when the probability calculus pretest was included as a covariate, no significant group difference with respect to learning results emerged (analysis of covariance: $F[1,33]<1)$.*

In order to test whether a variable can be regarded as mediator, the following rationale is used: A mediator has to be: (1) significantly associated with the teaching expectancy; (2) significantly associated with the learning results; and (3) the association between teaching expectancy and learning results is significantly changed when controlling for the mediator (cf. Baron \& Kenny, 1986). The only variable that is significantly (at least at the $10 \%$ level) associated with teaching expectancy and learning results is state anxiety. However, even this variable cannot be regarded as pivotal mediator, because the relation between experimental variation and learning results (expressed as biserial correlation: .00 , n.s.) was not significantly changed when controlling for state anxiety (partial correlation: .07, n.s.). Thus, the mediational link from teaching expectancy over state anxiety to learning results was very weak.

\section{Discussion}

The course of discussion corresponds to the sequence of research questions.

(1) According to the present results, a teaching expectancy does influence learning processes. Three out of five variables that characterize the learning processes were

\footnotetext{
*A possible explanation for the insignificant experimental effect on learning results may be that the teaching expectancy fosters learning only if it does not elicit negative motivational-affective states. In statistical terms this post-hoc hypothesis corresponds to a significant interaction effect between teaching expectancy (treatment condition) and the motivational-affective variables. However, analyses of covariance (dependent: post-test; factors: experimental variation and one motivational-affective variable per analysis; covariate: pretests) did not yield any significant interaction effects for neither of the motivational-affective variables.
} 
affected by the teaching expectancy. However, from an educational point of view, there were not only positive effects. On the one hand, persons with teaching expectancy were less superficial when studying worked-out examples. On the other hand, they did it with less intrinsic motivation and somewhat more anxiety. The latter result parallels the findings by Ross and DiVesta (1976) who also found this negative consequence of a teaching expectancy. The reduced intrinsic motivation of the persons with teaching expectancy is in sharp contrast to the study of Benware and Deci (1984) who found a strong positive effect with respect to intrinsic motivation. In that study the subjects could learn from a text on brain functioning at home. In the present study, the intrinsic motivation may have been depressed, because understanding the mathematics problems within a constrained time in the laboratory was perceived as difficult by the students of education and, at the same time, the pressure to understand the worked-out examples was high under teaching expectancy. Thus, the feelings of competence and of selfdetermination, which are important for the elicitation of intrinsic motivation (Ryan, Connell, \& Deci, 1985), may have been low, compared to the study of Benware and Deci (1984).

(2) The motivational-affective variables (i.e., state anxiety, worry, and intrinsic motivation) are all significantly associated with each other. Somewhat surprisingly, the cognitive indicators of the learning processes were neither related to each other nor, with one exception, to the motivational-affective variables. It is also interesting to note that the mediators were not associated with prior knowledge, except for problem elaboration and worry that correlates negatively with prior knowledge in probability calculus. The extent of problem elaboration was found to be positively associated with indicators of domain-specific competence in probability calculus. It was not, however, crucial for further learning, as indicated by the non-significant partial correlation between initial problem elaboration and learning results controlling for prior mathematical knowledge. Somewhat surprising is the negative correlation between initial problem elaboration and the algebra pretest. Conceivably, high prior algebraic knowledge speeds up the encoding of the computational aspects of the problems.

(3) The learning results are related to three out of five variables pertaining to the learning process. Persons who assign much time to initial problem elaboration tend to be successful in the post-test. Part of this effect is, however, due to the relatively high prior knowledge of these persons. This finding is in accord with research on expertise (Bédard \& Chi, 1992). The measures of anxiety were also related to the learning results, albeit this is more clearly true for worry than for state anxiety. This pattern of results is in accord with research on test anxiety (cf. the meta-analysis on the relation between anxiety and achievement by Seipp \& Schwarzer, 1991). The latter attributes a more important role to the cognitive component of achievement anxiety (i.e., worry) with respect to learning.

Surprisingly, the superficiality of processing was not related to the learning results. Maybe the indicator chosen in this study involved different aspects. A fast pace in studying the examples may have positive as well as negative effects. On the one hand, the subjects with a rapid pace did not explain the individual examples to themselves in a way that fosters learning. On the other hand, they had the opportunity to learn from diverse problems with different surface structures. According to the results by Catrambone and Holyoak (1989), learning from different problems with varying surface 
structures and constant deep structure fosters the induction of an abstract schema and, therefore, transfer. Thus, a fast studying of individual examples may have advantages that compensate for disadvantages. In order to test this post-hoc explanation, an in-depth study on learning processes is necessary.

Another astonishing finding is the lacking association between intrinsic motivation and learning which is in contrast to many other studies (for an overview see Schiefele $\&$ Schreyer, 1994). One reason for this difference may be that in the present study, due to experimental constraints, no influence of intrinsic motivation on the learning time was possible. In addition, as the meta-analysis of Schiefele and Schreyer (1994) showed, intrinsic motivation is consistently, but merely weakly associated with learning gains. Hence, big sample sizes, as are typical of field or survey studies, are often necessary to obtain significant relations between intrinsic motivation and learning, given the small practical significance of this effect.

(4) Unfortunately, no significant mediators can be identified in this study, although it has become clear that the teaching expectancy has some effects on variables related to learning. A fact that made the evaluation of mediator effects difficult is the relatively small sample size of this study. Structural modelling techniques (e.g., LISREL) which are an adequate means to statistically model mediator effects require more subjects than those available in this study. However, before conducting a larger study, a fruitful step following this exploratory study is to investigate the learning processes more directly by analyzing think aloud protocols that are recorded during learning. This will be the next step of the research program of which this study is a part. Based on the present results and the findings of the planned protocol analyses, a confirmatory study using structural modelling techniques can be conducted.

(5) The present study enlarged the number of investigations that failed to find a positive effect of a teaching expectancy. The learning results were not affected by the teaching expectancy. The insignificant group difference could not, according to the present findings, be attributed to different paths that compensated for each other. Instead, no single mediational link proved to be of real significance.

The results found in this study are also relevant to the frequent recent claims for social learning arrangements, such as peer tutoring and cooperative learning, in order to foster deep understanding (e.g., Mandl, Gruber, \& Renkl, in press). A teaching expectancy that is evoked by these learning arrangements, may elicit anxiety and, in addition, lower intrinsic motivation. Two plausible reasons can be suggested to account for the negative effects detected in the present study. Firstly, the beginning students of education had to learn mathematical contents perceived as difficult. Secondly, they were forced to adopt the unfamiliar role of a tutor. Probably, persons who are more experienced with respect to social learning arrangements would not be distressed in such a way by a teaching expectancy. Probably, the detrimental effects of the teaching expectancy are partly due to the neglect of social learning arrangements in school, especially in Germany (Huber, 1993). Even if, as in the present study, the negative motivational effects do not influence the learning results, they are detrimental with respect to long-term motivation for learning. The latter is surely negatively affected by lack of intrinsic motivation and anxiety (cf. Beitinger, Mandl, \& Renkl, 1993). In summary, if students have negative attitudes towards a subject matter and have little experience with social learning arrangement, it cannot be expected that social forms of 
learning will have positive effects only. There seems to be a need for fostering learning how to learn in social arrangements.

Acknowledgements - This research was funded by the Deutsche Forschungsgemeinschaft (DFG, Re 1040/1-1).

I thank Patricia Friederichs for collecting the data.

\section{References}

Aronson, E. (1984). Förderung von Schulleistung, Selbstwert und prosozialem Verhalten: Die JigsawMethode (Fostering of school achievement, self-respect, and pro-social behavior: The jigsaw method). In G. L. Huber, S. Rotering-Steinberg, \& D. Wahl (Eds.), Kooperatives Lernen (pp. 48-59). Weinheim: Beltz.

Aronson, E., Blaney, N., Stephan, C., Sikes, J., \& Snapp, M. (1978). The jigsaw classroom. Beverley Hills, CA: Sage.

Bargh, J. A., \& Schul, Y. (1980). On the cognitive benefits of teaching. Journal of Educational Psychology, 72, 593-604.

Baron, R. M., \& Kenny, D. A. (1986). The moderator-mediator variable distinction in social psychological research: Conceptual, strategic, and statistical considerations. Journal of Personality and Social Psychology, 51, 1173-1182.

Bédard, J., \& Chi, M. T. H. (1992). Expertise. Psychological Science, 1, 135-139.

Beitinger, G., Mandl, H., \& Renkl, A. (1993). Suggestopädischer Unterricht - eine empirische Studie zu kognitiven, motivational-emotionalen und sozialen Auswirkungen (Suggestopedic instruction - an empirical study on cognitive, motivational-emotional, and social effects). Unterrichtswissenschaft, 21, 195-214.

Benware, C. A. \& Deci, E. L. (1984). Quality of learning with an active versus passive motivational set. American Educational Research Journal, 21, 755-765.

Brown, A. L., \& Campione, J. C. (1990). Communities of learning and thinking, or a context by any other name. Contributions to Human Development, 21, 108-126.

Catrambone, R., \& Holyoak, K. J. (1989). Overcoming contextual limitations on problem-solving transfer. Journal of Experimental Psychology: Learning, Memory, and Cognition, 15, 1147-1156.

Chi, M. T. H., Bassok, M., Lewis, M. W., Reimann, P., \& Glaser, R. (1989). Self-explanations: How students study and use examples in learning to solve problems. Cognitive Science, 13, 145-182.

Comenius, J. A. (1957). Magna didactica. Berlin: Volk und Wissen.

Deci, E. L., Vallerand, R. J., Pelletier, L. G., \& Ryan, R. M. (1991). Motivation and education: The self-determination perspective. Educational Psychologist, 26, 325-346.

Ehly, S., Keith, T. Z., \& Bratton, B. (1987). The benefits of tutoring: An exploration of expectancy and outcomes. Contemporary Educational Psychology, 12, 131-134.

Fantuzzo, J. W., Riggio, R. E., Connelly, S., \& Dimeff, L. A. (1989). Effects of reciprocal peer tutoring on academic achievement and psychological adjustment: A component analysis. Journal of Educational Psychology, 81, 173-177.

Fantuzzo, J. W., King, J. A., \& Heller, L. R. (1992). Effects of reciprocal peer tutoring on mathematics and school adjustment: A component analysis. Journal of Educational Psychology, 84, 331-339.

Goodlad, S., \& Hirst, B. (1989). Peer tutoring: A guide to learning by teaching. London: Kogan.

Gräsel, C. (1990). Kohärenzbildung beim Lesen von Informationstexten (Construction of coherence in reading texts) (Unpublished master thesis). Munich: Ludwig-Maximilians-Universität.

Gruber, H. (1994). Klausurangst, subjektive Verstehenseinschätzung und Prüfungsleistung von Pädagogikstudenten in der. Methodenausbildung (Exam anxiety, perceived understanding, and achievement of students of education in a course on empirical methods). In R. Olechowski \& B. Rollett (Eds.), Theorie und Praxis. Aspekte empirisch-pädagogischer Forschung - quantitative und qualitative Methoden (pp. 184-189). Frankfurt am Main: Lang.

Huber, G. L. (1993). Europäische Perspektiven für kooperatives Lerner (European perspectives for cooperative learning). In G. L. Huber (Ed.), Neue Perspektiven der Kooperation (pp. 244-259). Hohengehren: Schneider.

Kafai, Y., \& Harel, I. (1991a). Children learning through consulting: When mathematical ideas, knowledge of programming and design, and playful discourse are intertwined. In I. Harel \& S. Papert (Eds.), Constructionism (pp. 111-140). Norwood, NJ: Ablex. 


\title{
LEARNING FOR LATER TEACHING: AN EXPLORATION OF MEDIATIONAL LINKS BETWEEN TEACHING EXPECTANCY AND LEARNING RESULTS
}

\author{
ALEXANDER RENKL
}

\author{
University of Munich, Germany
}

\begin{abstract}
It was investigated to what extent the expectancy of a teaching demand influences learning results. In addition, possible mediator effects were explored. Thirty-six subjects (students of education) learned from worked-out examples in the domain of probability calculus under two different conditions: The experimental group expected to be required to explain similar worked-out examples to a third person, whereas the control group merely anticipated to be tested on similar problems. The results showed that the teaching expectancy decreased the superficiality of studying the worked-out examples, lowered intrinsic motivation, and increased, to some extent, anxiety during learning. The learning results were negatively influenced by anxiety during learning and were positively associated with the time allocated to construct a sound problem representation. However, no assumed mediator effect proved to be of real significance. In addition, the learning gains were not affected by the teaching expectancy.
\end{abstract}

\section{Introduction}

\begin{abstract}
"Who teaches others, educates himself", and not only because he consolidates the acquired knowledge by repetition, but also because he gets the opportunity to immerse more deeply into the subject (Comenius, 1957, p. 172; author translation).
\end{abstract}

To regard teaching as an effective way of learning has a long tradition in pedagogy, as the above quotation from Comenius' (1592-1670) Magna didactica shows. Meanwhile, two research traditions have provided empirical evidence for this claim. The first tradition pertains to studies on tutoring. Several research projects have shown that tutors substantially profited from their teaching experience (for an overview, see Goodlad \& Hirst, 1989), from designing software for others (Kafai \& Harel, 1991b), or from consulting (Kafai \& Harel, 1991a). The second branch of research involves studies on cooperative learning. Many cooperative learning arrangements contain learning by

Address for correspondence: Dr A. Renkl, Institut für Pädagogische Psychologie und Empirische Pädagogik, Leopoldstraße 13, 80802 Munich, Germany (e-mail: renkl@mip.paed.uni-muenchen.de). 
Kafai, Y., \& Harel, I. (1991b). Learning through design and teaching. Exploring social and collaborative aspects of constructionism. In I. Harel \& S. Papert (Eds.), Constructionism (pp. 84-110). Norwood, NJ: Ablex.

Lambiotte, J. G., Dansereau, D. F., O’Donnell, A. M., Young, M. D., Skaggs, L. P., Hall, R. H., \& Rocklin, T. R. (1987). Manipulating cooperative scripts for teaching and learning. Journal of Educational Psychology, 79, 424-430.

Laux, L., Glanzmann, P., Schaffner, P., \& Spielberger, C. D. (1981). Das State-Trait-Angstinventar. Theoretische Grundlagen und Handanweisung (The state-trait anxiety inventory. Theoretical foundation and manual). Weinheim: Beltz.

Lienert, G. A., \& Hofer, M. (1977). Mathematiktest für Abiturienten und Studienanfänger. M-T-A-S (Mathematics test for 13th graders and university freshmen). Göttingen: Hogrefe.

Mandl, H., \& Ballstaedt, H.-P. (1982). Effects of elaboration on recall of texts. In A. Flammer \& W. Kintsch (Eds.), Discourse processing (pp. 482-494). Amsterdam: North-Holland.

Mandl, H., Gruber, H., \& Renkl, A. (in press). Communities of practice towards expertise: Social foundation of university instruction. In P. B. Baltes \& U. Staudinger (Eds.), Interactive minds: Life-span perspectives on the social foundation of cognition. Cambridge, MA: Cambridge University Press.

O'Donnell, A. M., \& Dansereau, D. F. (1992). Scripted cooperation in student dyads: A method for analyzing and enhancing academic learning and performance. In R. Hertz-Lazarowitz \& N. Miller (Eds.), Interactions in cooperative groups: Theoretical anatomy of group learning (pp. 12()-1+1). Cambridge, MA: Cambridge University Press.

Palincsar, A. S., \& Brown, A. L. (1984). Reciprocal teaching of comprehension-fostering and comprehensionmonitoring activities. Cognition and Instruction, 1, 117-175.

Prenzel, M., Eitel, F., Holzbach, R., Schoenheinz, R. J., \& Schweiberer, L. (1993). Lernmotivation im studentischen Unterricht in der Chirurgie (Motivation for learning in university instruction in surgery). Zeitschrift für Pädagogische Psychologie, 7, 125-137.

Reimann, P., \& Schult, T. (1991). Modelling example elaboration strategies. In L. Birnbaum (Ed.), The International Conference on the Learning Sciences. Proceedings of the 1991 Conference (pp. 375-381). Charlottesville, VA: Association for the Advancement of Computing in Education.

Renkl, A. (1994). Wer hat Angst vorm Methodenkurs? Eine empirische Studie zum Streßerleben von Pädagogikstudenten in der Methodenausbildung (Who is afraid of the training in research methods? An empirical study on perceived stress of students of education in a course on empirical research methods). In R. Olechowski \& B. Rollett (Eds.), Theorie und Praxis. Aspekte empirisch-pädagogischer Forschung - quantitative und qualitative Methoden (pp. 178-183). Frankfurt am Main: Lang.

Ross, S. M., \& DiVesta, F. J. (1976). Oral summary as a review strategy for enhancing recall of textual material. Journal of Educational Psychology, 68, 689-695.

Ryan, R. M., Connell, J. P., \& Deci, E. L. (1985). A motivational analysis of self-determination and self-regulation in education. In C. Ames \& R. Ames (Eds.), Research on motivation in education. The classroom milieu (Vol. 2, pp. 13-51). Orlando: Academic Press.

Schiefele, U., \& Schreyer, I. (1994). Intrinsische Lernmotivation und Lernen. Ein Überblick zu Ergebnissen der Forschung (Instrinsic motivation and learning. An overview of research results). Zeitschrift für Pädagogische Psychologie, 8, 1-13.

Schommer, M., Crouse, A., \& Rhodes, N. (1992). Epistemological beliefs and mathematical text comprehension: Believing it is simple does not make it so. Journal of Educational Psychology, 84, 435-443.

Seipp, B., \& Schwarzer, C. (1991). Angst und Leistung - Eine Meta-Analyse empirischer Befunde (Anxiety and achievement - A meta-analysis on empirical findings). Zeitschrift für Pädagogische Psychologie, $5,85-97$.

Zeidner, M. (1991). Statistics and mathematics anxiety in social science students: Some interesting parallels. British Journal of Educational Psychology, 61, 319-328.

Zhu, X., \& Simon, H. A. (1987). Learning mathematics from examples and by doing. Cognition and Instruction, 4, 137-166. 